\title{
EDITORIAL
}

\section{The nose and OSA: variable nasal obstruction may be more important in pathophysiology than fixed obstruction}

\author{
W.T. McNicholas
}

$\mathbf{T}$ he nose is the primary route of breathing in mammals and serves important physiological functions, which include heating, humidification and filtration of the inspired air [1,2]. As a consequence, humans naturally breathe through the nose, particularly during sleep, during which breathing is under automatic control and devoid of conscious influences. In normal subjects, the nasal airway accounts for $\geqslant 50 \%$ of total airway resistance, with most of this contribution arising from the anterior part of the nose, including the nasal valve [3]. The cross-sectional area of the nasal valve is controlled by several dilator muscles. In pathological conditions, nasal resistance may be considerably increased, with the extreme being total obstruction. Nasal resistance typically varies from one side to the other as a consequence of cyclical mucosal changes in the nasal turbinates, and with a cycle frequency of 2-4 h [4]. This nasal cycle may play a role in respiratory defence by the generation of plasma exudates [5]. Furthermore, nasal resistance diminishes during exercise as a consequence of sympathetically mediated mucosal vasoconstriction [6]. In contrast, nasal resistance increases in the supine position as a consequence of mucosal congestion [7]. These considerations indicate that the nose is a reactive organ with considerable potential to vary airflow resistance, which may have important implications for breathing, particularly during sleep.

Sleep represents a state of naturally increased nasal resistance caused by the supine position and decreased skeletal muscle tone, which may increase the component of nasal resistance that relates to the nasal valve. Nasal breathing has a stimulant effect on breathing and has been reported to be associated with a higher minute ventilation and flow rate compared with mouth breathing $[8,9]$. This effect appears to be mediated by local nasal reflexes. Ventilatory responses to hypoxia and hypercapnia are lower when nose breathing as compared to mouth breathing, and the difference is abolished by surface anaesthesia of the upper airway [9]. Upper airway dilating muscle activity has been reported to be higher during nasal compared to oral breathing, even under conditions in which an added resistance is applied to the oral route [10]. Diaphragmatic activity was not different and the effect was

STATEMENT OF INTEREST: None declared.

CORRESPONDENCE: W.T. McNicholas, Respiratory Sleep Disorders Unit, St. Vincent's University Hospital, Elm Park, Dublin 4, Ireland. Fax: 353 12697949. E-mail: walter.mcnicholas@ucd.ie eradicated by nasal surface anaesthesia, indicating a local reflex mechanism. SHI et al. [11] found no difference in genioglossus electromyogram activity breathing through the nose or mouth during exercise.

Interactions between nasal and oral resistance also occur that may have implications for the pathophysiology of obstructive sleep apnoea (OSA). For example, tongue protrusion has been reported to lower nasal airflow resistance in patients with OSA syndrome (OSAS) but not in normal subjects, and it is likely that the effect in OSAS reflects a lowering of resistance in the posterior nasal airway [12].

\section{THE UPPER AIRWAY AS A FORM OF STARLING RESISTOR}

The primary determinant of upper airway patency is the balance of forces between the negative pressure within the pharynx during inspiration and the counteracting force of upper airway dilator muscles, principally the genioglossus [13]. The upper airway has also been described as behaving like a Starling resistor [14]. This model views the upper airway as a hollow tube with a partial obstruction at the inlet, corresponding to the nose, and a collapsible section downstream, corresponding to the oropharynx. According to this model, when air is drawn through the narrowed inlet, greater suction forces are generated downstream and may contribute to the collapsing forces that affect the collapsible segment (fig. 1). Thus, when nasal obstruction develops, the downstream collapsibility of the oropharynx may be increased. However, there are a number of factors that reduce the significance of this upstream resistance on oropharyngeal collapsibility, not least the fact that the mouth represents an alternative route of breathing that can come into play when nasal resistance exceeds a critical point. Other forces, such as hysteresis and local surface tension forces within the pharynx, can also limit the effect of nasal resistance on oropharyngeal collapsibility.

\section{ORAL VERSUS NASAL BREATHING DURING SLEEP}

In normal subjects, upper airway resistance is lower during sleep when breathing through the nose as opposed to the mouth; this contrasts with the awake state, in which the resistance has been found to be equal in a study that compared resistance between sleep and wake in the same subjects [15]. Thus, individuals can be expected to make subconscious (automatic) efforts to breathe through the nose unless the 


$$
\text { Trachea }
$$

$$
\text { Pharynx }
$$

Nose

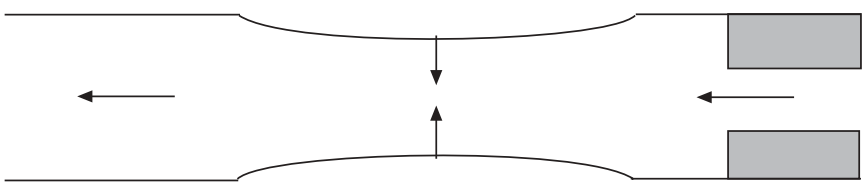

FIGURE 1. The Starling resistor model of upper airway collapsibility. The upper airway behaves like a Starling resistor in that obstruction at the inlet (i.e. the nasal airway) produces collapsing forces that are manifest downstream in the collapsible segment, the pharynx.

degree of obstruction is high enough to result in an unacceptably high work of breathing. In that situation, an adaptive response may result in an automatic switch to oral breathing once a particular threshold of nasal airflow resistance is exceeded. The mechanisms regulating the transition from nasal to oral breathing and the partitioning of breathing between the nasal and oral routes have not been extensively studied, in normal subjects or in patients with nasal disorders. However, combined recording of oral and nasal breathing, which can be performed with some commercial polysomnography (PSG) systems, indicates that subjects typically partition flow between nasal and oral routes, with the majority of airflow occurring through the nasal route. This has been quantified in a report by FITZPATRICK et al. [16] who found that the oral fraction of breathing averaged $7.6 \%$ in awake subjects, and fell to $4.3 \%$ during sleep.

\section{ROLE OF NASAL OBSTRUCTION IN THE PATHOPHYSIOLOGY OF OSA}

The pathophysiological mechanisms involved in OSA are complex and not fully understood. Critical upper airway narrowing/collapse usually occurs in the oropharynx, between the nasal choanae and epiglottis, an area that lacks rigid support [17]. Patency of this vulnerable segment is dependent on the action of the pharyngeal dilator and abductor muscles, which are usually activated in a rhythmic fashion during each inspiration [18]. Collapse of the upper airway occurs if the negative upper airway pressure generated by inspiratory pump muscles exceeds the dilating force of these upper airway muscles [18, 19]. Such upper airway narrowing requires an increase in pharyngeal dilator muscle contraction to maintain airway patency, and there is evidence that patients with OSAS have more forceful contraction of these muscles during wakefulness than normal subjects but show a larger decrement in contraction during sleep, thus contributing to the development of obstructive apnoea [20]. Studies that use nasal and oral flow-volume loops have indicated flow limitation via the nasal route in OSAS patients compared to normal subjects, particularly during expiration; it has also been shown that the degree of nasal flow limitation correlated with the apnoea/ hypopnoea index (AHI) [21]. Positional influences may also be important, as there is evidence that supine nasal resistance is more closely related to OSA [21, 22].

There is evidence of an interaction between nasal obstruction and pharyngeal narrowing in the pathophysiology of OSA. In a study of snorers, VIRKKULA et al. [23] found an independent relationship between nasal resistance, pharyngeal airspace and AHI. LiISTRO et al. [24] also reported a relationship between nasal obstruction, pharyngeal narrowing and AHI in 202 subjects referred with clinical suspicion of sleep-disordered breathing (SDB); pharyngeal narrowing was significantly related to AHI only in patients with nasal obstruction. MORRIS et al. [25] reported that measurements of nasal volume using acoustic rhinometry only correlated with respiratory disturbance index measurements in nonobese subjects. These findings suggest that obesity may mask a possible independent effect of nasal obstruction in the pathophysiology of OSA.

\section{VARIABLE OR FIXED NASAL OBSTRUCTION AND OSA}

The relationship between nasal obstruction and OSA has been a topic of considerable debate for many years. While the Starling resistor model of upper airway mechanics favours an important role for nasal obstruction in the pathophysiology of OSA, the available literature provides inconsistent evidence to support this relationship. Although there are relatively few well-designed studies of the relationship between nasal obstruction and OSA, I believe there is sufficient evidence to suggest that conditions associated with variable nasal obstruction play a greater role in the pathophysiology of OSA than conditions associated with fixed obstruction. This view is at least partly based on the hypothesis that the putative adaptive response which facilitates the transition from nasal to oral breathing in conditions associated with high nasal resistance, may be more prominent in conditions associated with fixed obstruction, as the intermittent period of low nasal airflow resistance which occurs with variable nasal obstruction is likely to maintain a closer link with automatic nasal breathing. It is my hypothesis that an adaptive response associated with a switch to oral breathing limits the impact of nasal obstruction in the pathogenesis of OSA in subjects with severe fixed obstruction and may also account for the low success rate reported in surgical management of such patients.

What evidence is available to support the hypothesis that variable nasal obstruction plays a greater role in the pathophysiology of OSA than fixed obstruction? While several studies have examined the relationship between disorders associated with nasal obstruction and snoring and/or OSA, and have considered the impact of relief of nasal obstruction on OSA severity, many of these studies have taken the form of simple subjective reports, limiting the confidence in conclusions that can be drawn from them. Treatment studies of nasal obstruction that have included both subjective and objective reports of efficacy have generally reported more positive subjective responses as compared to objective responses in terms of impact on sleep-related variables. Thus, a reliable assessment of the relationship between nasal obstruction and sleep-related breathing disturbances should include objective measurements of sleep and breathing, and should ideally include objective measures of nasal obstruction and/or nasal airflow resistance.

\section{STUDIES OF THE ASSOCIATION BETWEEN NASAL OBSTRUCTION AND SDB Population-based studies}

Several large population-based studies have examined the relationship between nasal obstruction and SDB. The 
Wisconsin cohort study, which involved 911 subjects undergoing PSG, reported a 1.8 times higher level of SDB in subjects with symptomatic allergic rhinitis compared to those without nasal symptoms [26]. In a later study of 1,032 subjects, a significant relationship was reported between SDB on PSG and nasal obstruction of varying aetiologies [27]. In a study of 7,980 workers, Udaka et al. [28] reported a significant relationship between habitual observed apnoea and self-reported nasal obstruction of unspecified aetiology. While the initial Wisconsin report [26] involved subjects with variable nasal obstruction, it is likely that the later report [27] included patients with both fixed and reversible nasal obstruction. Thus, the available evidence from population studies supports a role for nasal obstruction in the pathophysiology of OSA, irrespective of aetiology.

\section{Disorders associated with reversible nasal obstruction}

Studies of nasal airflow resistance in patients with seasonal rhinitis have shown a relationship between the level of resistance and SDB severity [29]. Micro-arousals associated with SDB are also more frequent in subjects with seasonal rhinitis than controls [30]. In a case-control study, CANOVA et al. [31] reported a significantly higher prevalence of allergic rhinitis in OSAS patients compared with chronic obstructive pulmonary disease patients. These data support a relationship between reversible nasal obstruction and SDB.

\section{Disorders associated with fixed nasal obstruction}

Objective studies of patients with fixed nasal obstruction offer little information about the relationship between such obstruction and SDB. ATKINS et al. [32] found no relationship between nasal resistance and SDB in OSAS patients and nonapnoeic snorers, but only a minority of their patients had significant nasal obstruction. These observations, taken in the context of other studies showing significant relationships of variable nasal obstruction with SDB, provide indirect support for the notion that fixed nasal obstruction is less important than variable obstruction in the pathophysiology of OSA.

\section{Artificially induced nasal obstruction}

Iatrogenic nasal obstruction is a particular form of reversible nasal obstruction in which obstruction is induced by nasal packing or external compression. Studies assessing the impact of artificially induced nasal obstruction during sleep in normal subjects and of nasal packing after nasal surgery, have consistently reported higher levels of SDB during the period of obstruction. Three early reports of normal subjects during overnight sleep found a higher rate of SDB during nasal obstruction compared with a control unobstructed night [3335]. AHI was also found to be significantly higher during postoperative nasal packing after nasal septum surgery in both OSAS and non-OSAS patients when compared to preoperative values [36]. These data provide further support for a significant relationship between variable nasal obstruction and SDB.

\section{IMPACT ON SDB SEVERITY OF MEDICAL OR SURGICAL MANAGEMENT TO RELIEVE NASAL OBSTRUCTION}

Another way to assess the relationship of variable and fixed nasal obstruction with OSA is to assess the impact of relief of such obstruction on SDB severity. This topic has been addressed in recent systematic reviews [37, 38]. While there are a large number of reports that have evaluated various forms of medical and surgical interventions to alleviate nasal obstruction in patients with snoring and/or OSA, relatively few have employed an adequate study design that includes consecutive patient selection and objective assessment of treatment efficacy. Fewer still have included measures of nasal resistance and/or a randomised, placebo-controlled study design. Nevertheless, the available evidence suggest that studies of medical management of disorders associated with variable nasal obstruction, such as rhinitis, have reported a more consistent reduction in measures of OSA severity than studies of surgical correction of fixed deformities, such as deviated nasal septum.

\section{Studies of medical management of nasal obstruction}

A number of studies evaluating the impact of medical management of nasal obstruction on OSA severity have employed a randomised, placebo-controlled study design. Interventions include intranasal corticosteroids, decongestants and mechanical nasal dilators, and patient populations have included subjects with clinical OSAS coexisting with rhinitis, upper airway resistance syndrome (UARS) patients and rhinitis patients without objective evidence of SDB. Two randomised, placebo-controlled studies of the use of intranasal steroids in OSAS patients have demonstrated a significant fall in AHI with active therapy (table 1) [39, 40]; the report by KIELY et al. [39] indicated a good relationship between nasal airflow resistance measured using posterior rhinomanometry and AHI (fig. 2). Another study of rhinitis patients without OSAS found no difference in AHI between those using steroids and those given a placebo [44]. Two randomised, controlled trials have demonstrated the objective benefit of mechanical nasal dilators in patients with coexisting chronic rhinitis, one in nonapnoeic snorers [41] and the other in patients with OSAS [45]. Another randomised, controlled trial of nasal dilators in patients with UARS without clinical nasal obstruction found no difference in AHI, although desaturation time was reduced [41]. However, KERR et al. [46] reported no improvement in AHI or sleep quality following 1 night's reduction in nasal airflow resistance using a combination of nasal decongestant and vestibular stenting when compared to a placebo saline night. Overall, the evidence favours a significant objective benefit of the medical management of nasal obstruction, with the greatest benefits being observed in patients with coexisting OSAS and variable nasal obstruction. However, the benefit is generally limited and few patients gain complete resolution of OSAS.

\section{Studies of surgical management of nasal obstruction in patients with fixed nasal obstruction}

Only one study into surgical correction of fixed nasal obstruction as a means of treating SDB employed a randomised, controlled design. In a recent report that appeared in the European Respiratory Journal, KOUTSOURELAKIS et al. [43] performed a randomised, controlled trial of nasal surgery in patients with OSAS and found only a $15 \%$ success rate, with a positive outcome only occurring in patients exhibiting a high level of oral breathing during sleep in pre-operative sleep studies and a significant increase in post-operative nasal breathing in responders. These findings suggest that the ability 
TABLE 1 Randomised, placebo-controlled trials of medical and surgical therapies in sleep-disordered breathing

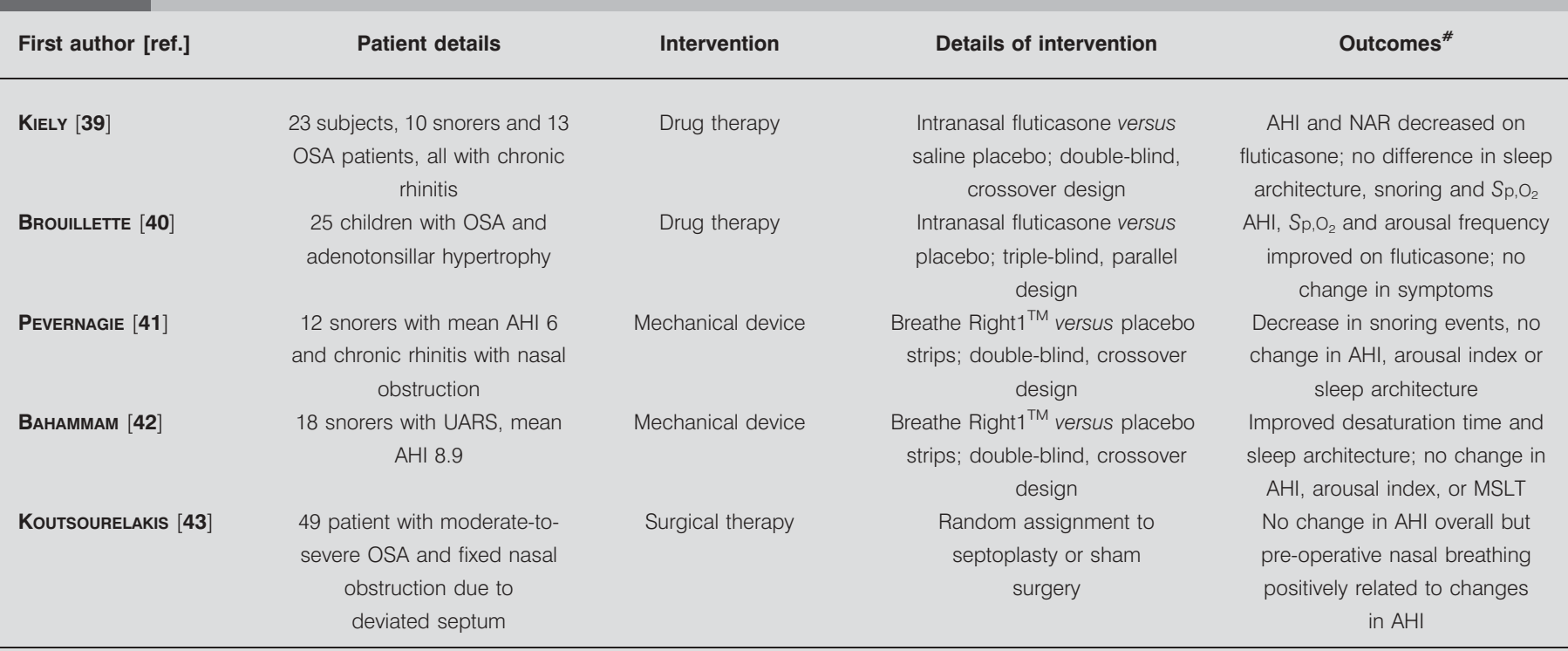

The studies presented are limited to those involving a randomised, double-blind (for nonsurgical studies) and placebo-controlled design, with objective sleep studies and a minimum treatment period of 1 week. Breathe Right $1^{\mathrm{TM}}$ manufactured by 3M, Borken, Germany. OSA: obstructive sleep apnoea; AHI: apnoea/hypopnoea index; NAR: nasal airflow resistance; $\mathrm{Sp}, \mathrm{O}_{2}$ : arterial oxygen saturation measured by pulse oximetry; UARS: upper airway resistance syndrome; MSLT: multiple sleep latency testing. ${ }^{\#}$. $\mathrm{p}<0.05$ considered to be statistically significant.

to switch from oral to nasal breathing when nasal airflow resistance is lowered represents an important determinant of a positive outcome of nasal surgery. Similar negative findings have been reported by three other nonrandomised studies, which included consecutive patient selection and objective assessment of SDB variables before and after surgery [47-49]. However, SERIES et al. [50] reported significant improvements in AHI following surgical relief of nasal obstruction in a group of mild OSAS patients who had normal pre-operative cephalometry. This finding supports the view that nasal obstruction is particularly important in OSA in the absence

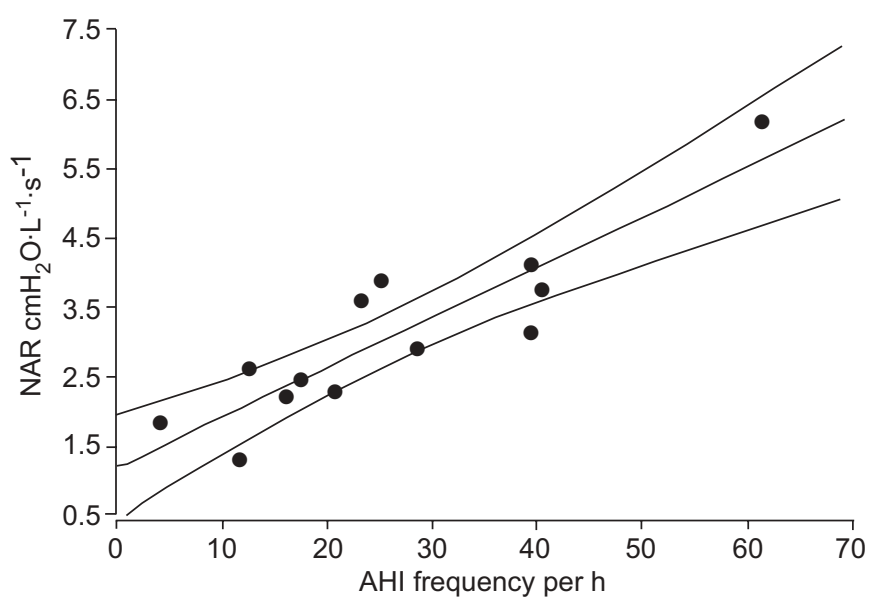

FIGURE 2. Correlation between mean pre- and post-sleep nasal airflow resistance in (NAR) and apnoea/hypopnoea frequency (apnoea/hypopnoea index $(\mathrm{AHI})$ ) in 13 patients with both rhinitis and obstructive sleep apnoea after 4 weeks of intranasal fluticasone therapy. $r=0.88 ; p<0.0001$. Data taken from [39]. of oropharyngeal narrowing and supports other reports demonstrating a relationship between the nose and pharynx in the pathophysiology of OSA. Surprisingly, there is a poor relationship between post-operative reduction in nasal resistance and changes in OSA severity [46, 47]. Thus, the overall conclusion from adequately designed studies of nasal surgery in OSA is that it has a low success rate, although carefully selected subgroups might benefit.

\section{PRIORITIES FOR FUTURE RESEARCH}

I agree with recent reports that nasal surgery is generally not indicated as a therapeutic option for OSAS but I also advocate a trial of medical therapy with intranasal corticosteroids and/or decongestants in OSAS and/or snoring patients with variable nasal obstruction. Further well-designed studies are needed in order to identify specific patient populations that may benefit from relief of nasal obstruction and to continue to test the hypothesis that OSAS patients with variable nasal obstruction obtain greater benefit from relief of nasal obstruction than patients with fixed nasal obstruction. In particular, there is a need for adequately powered randomised controlled studies of specific treatment interventions (medical or surgical), with relevant outcome measures that should include measurement of nasal airflow resistance and objective sleep studies before and after intervention. The choice of method for measuring nasal airflow resistance reflects a compromise between optimum measurements and practicality/ease of technique. While posterior rhinomanometry offers more complete information concerning nasal airflow resistance, the technique is technically difficult and, as a result, anterior rhinomanometry is more widely used. However, as the bulk of airflow resistance orginates in the anterior part of the nasal airway, this latter measurement is clinically useful. 
Adequately controlled studies of SDB are also required, which compare patients with specific disorders associated with nasal obstruction and matched normal subjects. In particular, and given the hypothesis presented in the present article, such studies should compare the prevalence of SDB in subjects with disorders associated with reversible nasal obstruction to those with fixed obstruction. A possible example would be to compare the level of SDB in patients with rhinitis to those with a deviated nasal septum, with each group matched in terms of important demographic variables and level of nasal airflow resistance.

At a more basic level, physiological studies are needed if we are to better understand the partitioning of nasal and oral breathing during sleep, and, in particular, the mechanisms regulating the transition from nasal to oral breathing in health and disease.

\section{REFERENCES}

1 Geurkink N. Nasal anatomy, physiology, and function. J Allergy Clin Immunol 1983; 72: 123-128.

2 Proctor DF. Nasal physiology and defence of the lungs. Am Rev Respir Dis 1977; 115: 97-129.

3 Ferris B, Mead J, Opie L. Partitioning of respiratory flow resistance in man. J Appl Physiol 1964; 19: 653-658.

4 Hasegawa M, Kern EB. Variations in nasal resistance in man: a rhinomanometric study of the nasal cycle in 50 human subjects. Rhinology 1978; 16: 19-29.

5 Eccles R. A role for the nasal cycle in respiratory defence. Eur Respir J 1996; 9: 371-376.

6 Widdicombe JG. The physiology of the nose. Clin Chest Med 1986; 7: 159-170.

7 Duggan CJ, Watson RA, Pride NB. Postural changes in nasal and pulmonary resistance in subjects with asthma. J Asthma 2004; 41: 701-707.

8 McNicholas W, Coffey M, Boyle T. Effects of nasal airflow on breathing during sleep in normal humans. Am Rev Respir Dis 1993; 147: 620-623.

9 Douglas NJ, White DP, Weil JV, Zwillich CW. Effect of breathing route on ventilation and ventilatory drive. Respir Physiol 1983; 51: 209-218.

10 Basner RC, Simon PM, Schwartzstein RM, Weinberger SE, Weiss JW. Breathing route influences upper airway muscle activity in awake normal adults. J Appl Physiol 1989; 66: 1766-1771.

11 Shi YX, Seto-Poon M, Wheatley JR. Breathing route dependence of upper airway muscle activity during hyperpnea. J Appl Physiol 1998; 84: 1701-1706.

12 Coste A, Lofaso F, d'Ortho MP, et al. Protruding the tongue improves posterior rhinomanometry in obstructive sleep apnoea syndrome. Eur Respir J 1999; 14: 1278-1282.

13 Ayappa I, Rapoport DM. The upper airway in sleep: physiology of the pharynx. Sleep Med Rev 2003; 7: 9-33.

14 Park SS. Flow-regulatory function of upper airway in health and disease: a unified pathogenetic view of sleepdisordered breathing. Lung 1993; 171: 311-333.

15 Fitzpatrick MF, McLean H, Urton AM, Tan A, O'Donnell D, Driver HS. Effect of nasal or oral breathing route on upper airway resistance during sleep. Eur Respir J 2003; 22: 827-832.
16 Fitzpatrick MF, Driver HS, Chatha N, Voduc N, Girard AM. Partitioning of inhaled ventilation between the nasal and oral routes during sleep in normal subjects. J Appl Physiol 2003; 94: 883-890.

17 Hudgel DW. Variable site of airway narrowing among obstructive sleep apnea patients. J Appl Physiol 1986; 61: 1403-1409.

18 Remmers JE, DeGroot WJ, Sauerland EK, Anch AM. Pathogenesis of upper airway occlusion during sleep. J Appl Physiol 1978; 44: 931-938.

19 Deegan PC, McNicholas WT. Pathophysiology of obstructive sleep apnoea. Eur Respir J 1995; 8: 1161-1178.

20 Mezzanotte WS, Tangel DJ, White DP. Influence of sleep onset on upper-airway muscle activity in apnea patients versus normal controls. Am J Respir Crit Care Med 1996; 153: 1880-1887.

21 Shepard JW Jr, Burger CD. Nasal and oral flow-volume loops in normal subjects and patients with obstructive sleep apnea. Am Rev Respir Dis 1990; 142: 1288-1293.

22 Virkkula P, Maasilta P, Hytönen M, Salmi T, Malmberg H. Nasal obstruction and sleep-disordered breathing: the effect of supine body position on nasal measurements in snorers. Acta Otolaryngol 2003; 123: 648-654.

23 Virkkula P, Hurmerinta K, Löytönen M, Salmi T, Malmberg H, Maasilta P. Postural cephalometric analysis and nasal resistance in sleep-disordered breathing. Laryngoscope 2003; 113: 1166-1174.

24 Liistro G, Rombaux P, Belge C, Dury M, Aubert G, Rodenstein DO. High Mallampati score and nasal obstruction are associated risk factors for obstructive sleep apnoea. Eur Respir J 2003; 21: 248-252.

25 Morris LG, Burschtin O, Lebowitz RA, Jacobs JB, Lee KC. Nasal obstruction and sleep-disordered breathing: a study using acoustic rhinometry. Am J Rhinol 2005; 19: 33-39.

26 Young T, Finn L, Kim H. Nasal obstruction as a risk factor for sleep disordered breathing. J Allergy Clin Immunol 1997; 99: S757-S762.

27 Young T, Finn L, Palta M. Chronic nasal congestion at night is a risk factor for snoring in a population-based cohort study. Arch Intern Med 2001; 161: 1514-1519.

28 Udaka T, Suzuki H, Fujimura T, et al. Relationships between nasal obstruction, observed apnea, and daytime sleepiness. Otolaryngol Head Neck Surg 2007; 137: 669-673.

29 McNicholas WT, Tarlo S, Cole P, et al. Obstructive apneas during sleep in patients with seasonal allergic rhinitis. Am Rev Respir Dis 1982; 126: 625-628.

30 Lavie P, Gertner R, Zomer J, Podoshin L. Breathing disorders in sleep associated with "microarousals" in patients with allergic rhinitis. Acta Otolaryngol 1981; 92: 529-533.

31 Canova CR, Downs SH, Knoblauch A, Andersson M, Tamm M, Leuppi JD. Increased prevalence of perennial allergic rhinitis in patients with obstructive sleep apnea. Respiration 2004; 71: 138-143.

32 Atkins M, Taskar V, Clayton N, Stone P, Woodcock A. Breath-holding time in normal subjects, snorers, and sleep apnea patients. Chest 1995; 107: 959-962.

33 Suratt PM, Turner BL, Wilhoit SC. Effect of intranasal obstruction on breathing during sleep. Chest 1986; 90: 324-329.

34 Lavie P, Fischel N, Zomer J, Eliaschar I. The effects of partial and complete mechanical occlusion of the nasal 
passages on sleep structure and breathing in sleep. Acta Otolaryngol 1983; 95: 161-166.

35 Zwillich CW, Pickett C, Hanson FN, Weil JV. Disturbed sleep and prolonged apnea during nasal obstruction in normal men. Am Rev Respir Dis 1981; 124: 158-160.

36 Regli A, von Ungern-Sternberg BS, Strobel WM, Pargger H, Welge-Luessen A, Reber A. The impact of postoperative nasal packing on sleep-disordered breathing and nocturnal oxygen saturation in patients with obstructive sleep apnea syndrome. Anesth Analg 2006; 102: 615-620.

37 Kohler M, Bloch KE, Stradling JR. The role of the nose in the pathogenesis of obstructive sleep apnoea and snoring. Eur Respir J 2007; 30: 1208-1215.

38 Rappai M, Collop N, Kemp S, deShazo R. The nose and sleep-disordered breathing: what we know and what we do not know. Chest 2003; 124: 2309-2323.

39 Kiely JL, Nolan P, McNicholas WT. Intranasal corticosteroid therapy for obstructive sleep apnoea in patients with co-existing rhinitis. Thorax 2004; 59: 50-55.

40 Brouillette RT, Manoukian JJ, Ducharme FM, et al. Efficacy of fluticasone nasal spray for pediatric obstructive sleep apnea. J Pediatr 2001; 138: 838-844.

41 Pevernagie D, Hamans E, Van Cauwenberge P, Pauwels R. External nasal dilation reduces snoring in chronic rhinitis patients: a randomized controlled trial. Eur Respir J 2000; 15: 996-1000.

42 Bahammam AS, Tate R, Manfreda J, Kryger MH. Upper airway resistance syndrome: effect of nasal dilation, sleep stage, and sleep position. Sleep 1999; 22: 592-598.
43 Koutsourelakis I, Georgoulopoulos G, Perraki E, Vagiakis E, Roussos C, Zakynthinos SG. Randomised trial of nasal surgery for fixed nasal obstruction in obstructive sleep apnoea. Eur Respir J 2008; 31: 110-117.

44 Craig TJ, Mende C, Hughes K, Kakumanu S, Lehman EB, Chinchilli V. The effect of topical nasal fluticasone on objective sleep testing and the symptoms of rhinitis, sleep, and daytime somnolence in perennial allergic rhinitis. Allergy Asthma Proc 2003; 24: 53-58.

45 McLean HA, Urton AM, Driver HS, et al. Effect of treating severe nasal obstruction on the severity of obstructive sleep apnoea. Eur Respir J 2005; 25: 521-527.

46 Kerr P, Millar T, Buckle P, Kryger M. The importance of nasal resistance in obstructive sleep apnea syndrome. J Otolaryngol 1992; 21: 189-195.

47 Virkkula P, Bachour A, Hytonen M, et al. Snoring is not relieved by nasal surgery despite improvement in nasal resistance. Chest 2006; 129: 81-87.

48 Friedman M, Tanyeri H, Lim J, et al. Effect of improved nasal breathing on obstructive sleep apnea. Otolaryngol Head Neck Surg 2000; 122: 71-74.

49 Series F, St Pierre S, Carrier G. Effects of surgical correction of nasal obstruction in the treatment of obstructive sleep apnea. Am Rev Respir Dis 1992; 146: 1261-1265.

50 Series F, Pierre S, Carrier G. Surgical correction of nasal obstruction in the treatment of mild sleep apnea: importance of cephalometry in predicting outcome. Thorax 1993; 48: 360-363. 